\title{
Bridging a Survey Redesign Using Multiple Imputation: An Application to the 2014 CPS ASEC
}

\author{
Jonathan Rothbaum ${ }^{1}$
}

\begin{abstract}
The Current Population Survey Annual Social and Economic Supplement (CPS ASEC) serves as the data source for official income, poverty, and inequality statistics in the United States. In 2014, the CPS ASEC questionnaire was redesigned to improve data quality and to reduce misreporting, item nonresponse, and errors resulting from respondent fatigue. The sample was split into two groups, with nearly $70 \%$ receiving the traditional instrument and $30 \%$ receiving the redesigned instrument. Due to the relatively small redesign sample, analyses of changes in income and poverty between this and future years may lack sufficient power, especially for subgroups. The traditional sample is treated as if the responses were missing for income sources targeted by the redesign, and multiple imputation is used to generate plausible responses. A flexible imputation technique is used to place individuals into strata along two dimensions: 1) their probability of income recipiency and 2) their expected income conditional on recipiency for each income source. By matching on these two dimensions, this approach combines the ideas of propensity score matching and predictive means matching. In this article, this approach is implemented, the matching models are evaluated using diagnostics, and the results are analyzed.
\end{abstract}

Key words: Multiple imputation; survey redesign; bridge; CPS ASEC.

\section{Introduction}

The Current Population Survey Annual Social and Economic Supplement (CPS ASEC) is among the most widely used surveys conducted by the U.S. Census Bureau. CPS ASEC data are used to calculate measurements of national income and the official poverty rate. Rothbaum (2015) shows that the CPS ASEC suffers from underreporting of certain income types, including property income (especially interest and dividends), retirement income, and income from means-tested government transfer programs. Meyer et al. (2009) also show underreporting of participation in means-tested government programs.

To address this underreporting, the U.S. Census Bureau, in consultation with the private sector, implemented a redesign of the survey (see Czajka and Denmead (2008) and Hicks and Kerwin (2011) for results of that consultation). In 2014, approximately $30 \%$ of the CPS ASEC sample received the redesigned survey instrument, and approximately $70 \%$

\footnotetext{
1 Social and Economic Housing Statistics Division, U.S. Census Bureau, 4600 Silver Hill Road, Washington, DC 20233, U.S.A. Email: jonathan.1.rothbaum@census.gov

Acknowledgments: This article is released to inform interested parties of ongoing research and to encourage discussion of work in progress. The views expressed on methodological or operational issues are those of the author and are not necessarily those of the U.S. Census Bureau. Any error or omissions are the sole responsibility of the author. Any views expressed on statistical, methodological, technical, or operational issues are those of the author and not necessarily those of the U.S. Census Bureau. All data used in this article are confidential.
} 
received the unchanged traditional instrument (in use since 1994). Assignment into the two groups was random at the household level. For more details about the redesign and the content tests, see Semega and Welniak (2013, 2015).

A major focus of the redesign was to improve reporting of property income, especially income earned from assets in the form of interest or dividends. In addition, since 1980, the nature of retirement savings has shifted from defined benefit to defined contribution plans. From 1980 to 2008, the share of private wage and salary workers with defined benefit plans fell from $38 \%$ to $20 \%$. The share of private workers with defined contribution plans grew from eight percent to $31 \%$ over the same period (Butrica et al. 2009). Therefore, the survey was redesigned to improve reporting of retirement income, which has also historically been underreported (Czajka and Denmead 2008).

The redesigned instrument is being used for the full sample, starting with the 2015 CPS ASEC. However, in order to make apples-to-apples comparisons between the results in 2014 and 2015 and beyond, only $30 \%$ of the 2014 sample can be used. This significantly reduces the power of the comparisons that can be made, for example of median income or poverty rates, and is especially relevant for subgroups.

While the survey redesign significantly increased recipiency and aggregates for many income types, the majority of income (by US dollars) was not affected. For example, earnings comprised $75.9 \%$ of all income in the redesign sample, and there were no statistically significant differences in the number of earners or mean earnings across the two instruments. Although we do not observe what respondents to the traditional instrument would have said to the redesigned questions, we do have a considerable amount of information about them that is unaffected by the redesign.

This suggests treating the problem as one of missing data - as if the recipients of the traditional instrument did not respond to the redesigned income questions. The "missing" responses to the redesigned questions are multiply imputed for individuals in the traditional sample. This article adds to the literature using multiple imputation to bridge a survey or data classification change. Clogg et al. (1991) used multiple imputation to impute industry and occupation codes across a change in the coding scheme between 1970 and 1980 census data. Schenker and Parker (2003) imputed single-race reporting for multiple-race respondents after a change from single- to multi-race reporting in government survey data.

An approach developed by Bondarenko and Raghunathan (2007) is applied to impute these missing responses in the traditional sample. This approach combines the ideas of propensity score matching and predictive means matching. By matching donors to recipients within propensity score/predictive mean cells, this approach is similar to the hot deck procedure used in normal CPS ASEC processing. That makes it appealing for use in this case, as the completed data from the 2014 CPS ASEC can be used to make comparisons with data in subsequent years where all imputation of missing values is done using the hot deck.

The Bondarenko and Raghunathan technique is used to create an "Income-Consistent" full file that uses all of the CPS ASEC sample with imputed income in the affected categories for respondents to the traditional instrument. It is called the Income-Consistent file, as the responses for all individuals are consistent with the questions in the redesign survey instrument.

The article is organized as follows. In Section 2, the CPS ASEC and the survey redesign are described. Section 3 discusses the imputation methodology. Section 4 discusses 
diagnostic results to evaluate the models used. Section 5 contains results relating to income and poverty, measurement using the imputed data. Section 6 contains a conclusion.

\section{Data and Survey Redesign}

The CPS ASEC is among the most widely used surveys conducted by the U.S. Census Bureau. The CPS ASEC uses a stratified random sample to survey about 100,000 households each year and includes questions on income and health insurance coverage.

The 2014 survey redesign included a number of changes. First, the survey was redesigned to specifically ask if anyone in the household has a pension, and separately if anyone has a retirement account (401(k), 403(b), IRA, or other account designed specifically for retirement savings). The traditional instrument includes one broad question on the receipt of pension and retirement income. The redesigned instrument also asks individuals over 70 years old about required distributions from retirement accounts. To ensure that the distribution is correctly identified as income, a follow-up question asks if the required distribution was "rolled over" or reinvested in another account. The traditional ASEC instrument makes no distinction between investment income received in retirement accounts or separately from them. This more detailed set of questions can improve misreporting of income and cue respondents to decrease underreporting.

Several additional changes were also made to the survey. Prior to the redesign, only households that reported less than USD 75,000 in combined family income were asked questions about means-tested transfer programs such as Temporary Assistance to Needy Families (TANF). Semega and Welniak (2015) cite evidence from the American Community Survey (ACS) that some screened households were likely to be recipients of these transfers making it inappropriate to remove them using the income screener. To prevent respondent fatigue from affecting answers to the income recipiency questions, the recipiency questions were separated from the amount questions as part of a "dual-pass" approach. Respondents were asked first about all sources of income received and then later were asked about amounts for only the received sources. In addition, the order of the income questions was changed based on respondent characteristics to match those sources most likely to be received. If a respondent was unsure of the income generated from assets, the value of the assets was collected. The questions on disability were clarified to eliminate confusion between disability income from Social Security and Supplemental Security Income (SSI).

\subsection{Results of the Redesign}

In 2014, the CPS ASEC sample was randomly divided into two groups at the household level, with $31 \%$ (30,000 housing units) receiving the redesigned instrument and about $69 \%$ $(68,000$ housing units) receiving the traditional instrument. Within each sample, individual observations were weighted to national population controls, as is standard with the CPS ASEC. Both surveys were conducted primarily by home visit (with some by phone) by trained field representatives. Even the interviewer was not aware of the selection of a given household into the traditional or redesign sample until they began the survey. 
Semega and Welniak (2015) compared income aggregates between the two samples. Table 1 shows a subset of their results for median income, updated to reflect recent edits of the redesign sample file. Household median income was USD 51,939 in the traditional sample and USD 53,585 in the redesign, a difference of 3.2\%. When decomposed by race, the only statistically significant differences are for whites (and non-Hispanic whites).

Table 2 shows income statistics for total income and various income sources collected in the CPS ASEC. For each source, Semega and Welniak report the number of recipients in the population, the mean income earned by those recipients, and the aggregate value of that income estimated, using the traditional and redesign samples separately. For example, for total income, the number of income recipients estimated using the traditional sample is 218.7 million compared with 222.0 from the redesigned sample, a statistically significant difference of $1.5 \%$. The estimated difference in mean total income is $2.6 \%$ (USD 41,319 in the traditional vs. USD 42,394 in the redesign), and the estimated difference in aggregate total income is $4.2 \%$ (USD 9.04 trillion in the traditional compared with USD 9.41 trillion in the redesign), both statistically significant. At the $90 \%$ confidence level, there are a number of income sources that have statistically significant differences in the number of recipients, mean income, or aggregate income. The sources with statistically significant differences in aggregate income include farm self-employment income $(-42.1 \%)$, public assistance $(28.8 \%)$, veterans' benefits $(-23.1 \%)$, disability benefits $(36.4 \%)$, retirement income $(21.9 \%)$, interest $(113.0 \%)$, and dividends $(-20.1 \%)$.

Mitchell and Renwick (2015) study the effects of the redesign on poverty rates. While they find no statistically significant difference in the overall poverty rate, they do find differences for child and elderly poverty in the redesigned sample. In both cases, they suggest that differences in the sample populations may explain the increase in poverty in the redesigned sample. For child poverty, they show that the redesigned sample has a higher share of children living with female householders than the traditional sample (single-mother families). They also find that means-tested program recipiency was higher in the redesigned sample.

These potential differences in sample characteristics support the approach taken in this article. Because the changes in the questionnaire are treated as a problem of missing information, any differences in the samples can be controlled for as a part of the imputation modeling, and the combined sample should better reflect the intended full CPS ASEC sample.

\subsection{Selection of Income Sources to be Imputed}

Taking these analyses together, the redesign increased aggregate income, increased income recipiency and reporting in a number of income categories. However, some of the differences, especially in income types with no or little change in the questionnaire, may be due to random variation or differences in the samples. This is supported by differences in poverty that Mitchell and Renwick attribute to sample differences.

Because of this evidence of sample differences, the analysis focuses on those income types which were targeted by the questionnaire redesign. This eliminates farm selfemployment, and veterans' benefits.

The income types that are sufficiently different between the two surveys and were specifically targeted by the questionnaire redesign include: 1) retirement income, 


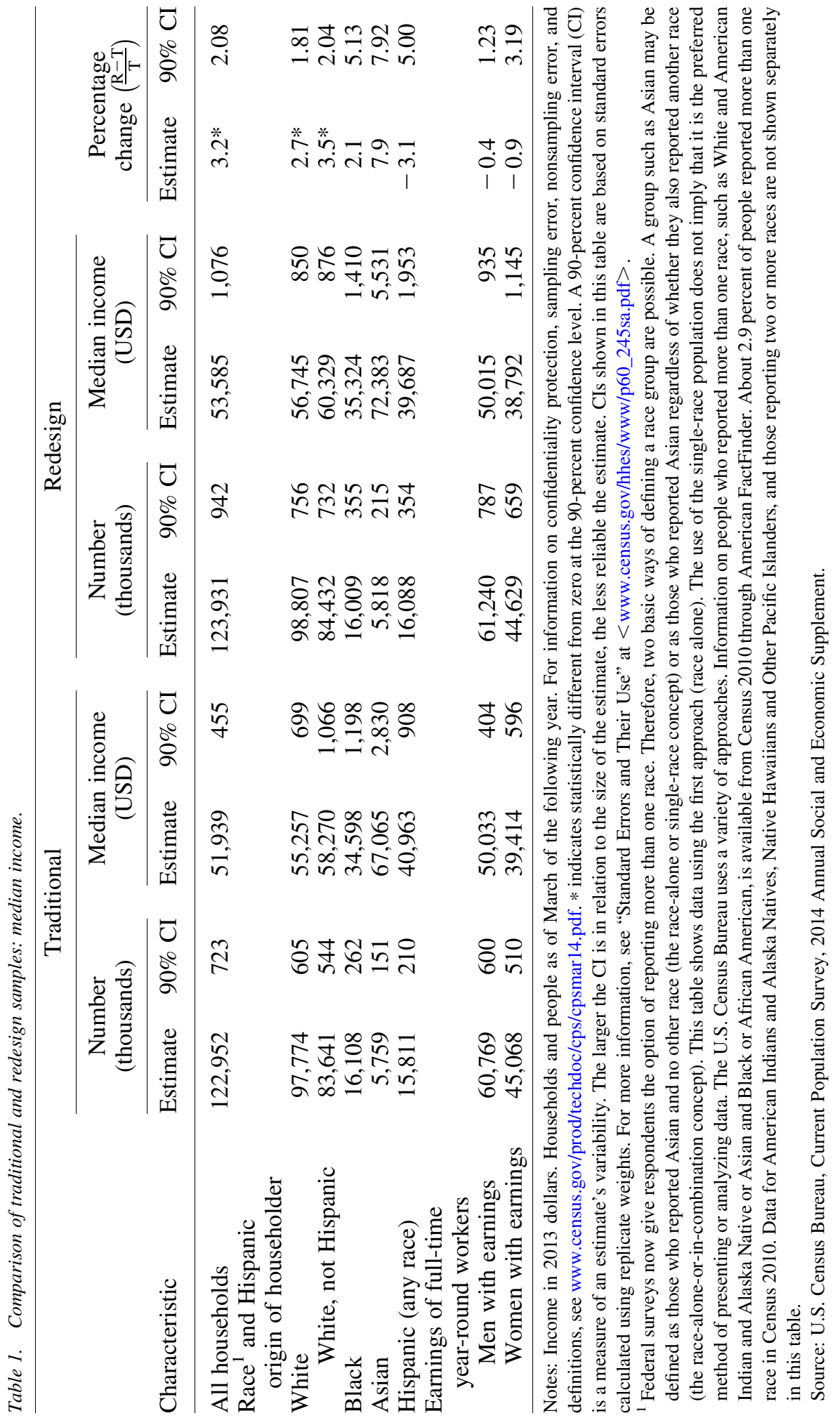




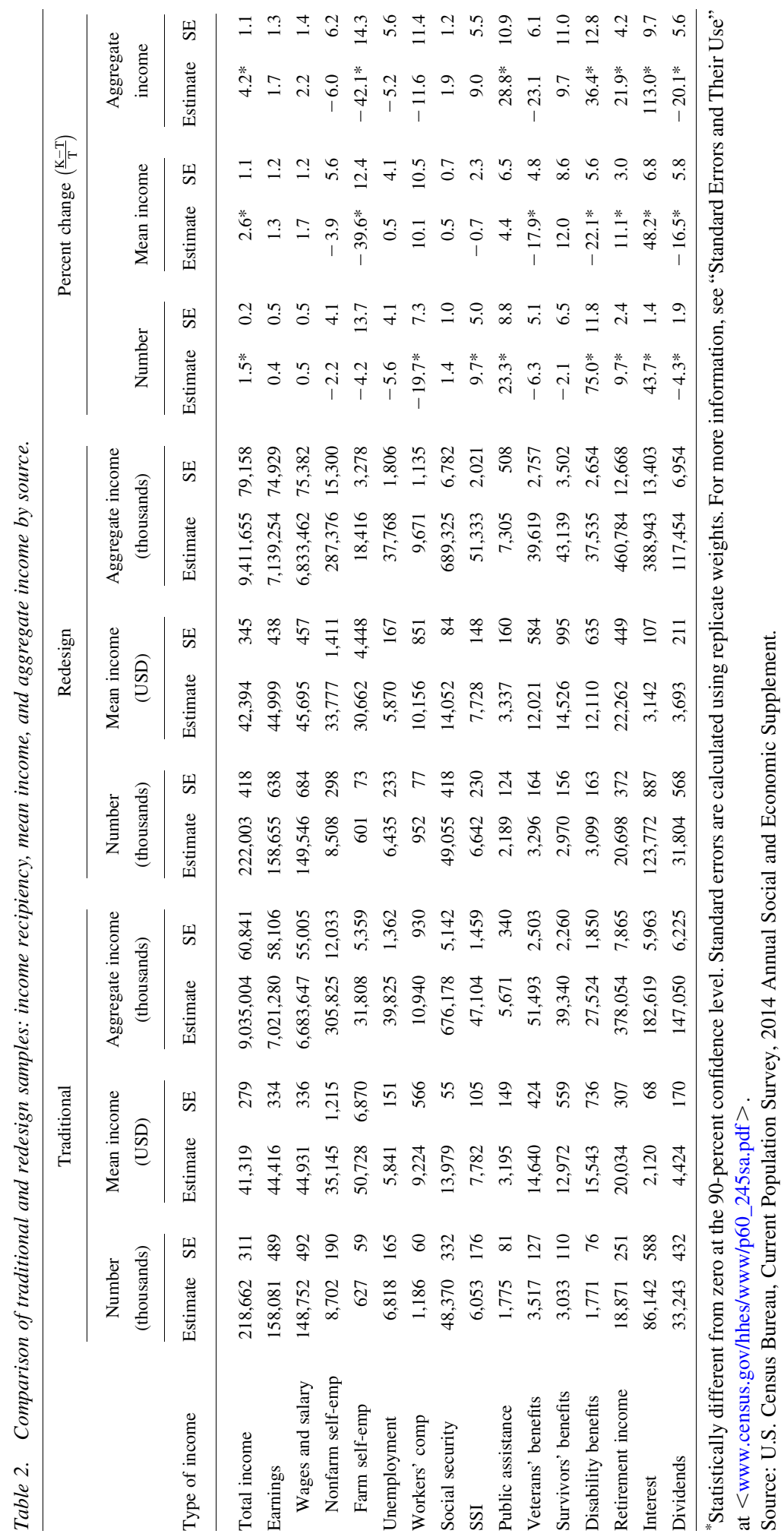




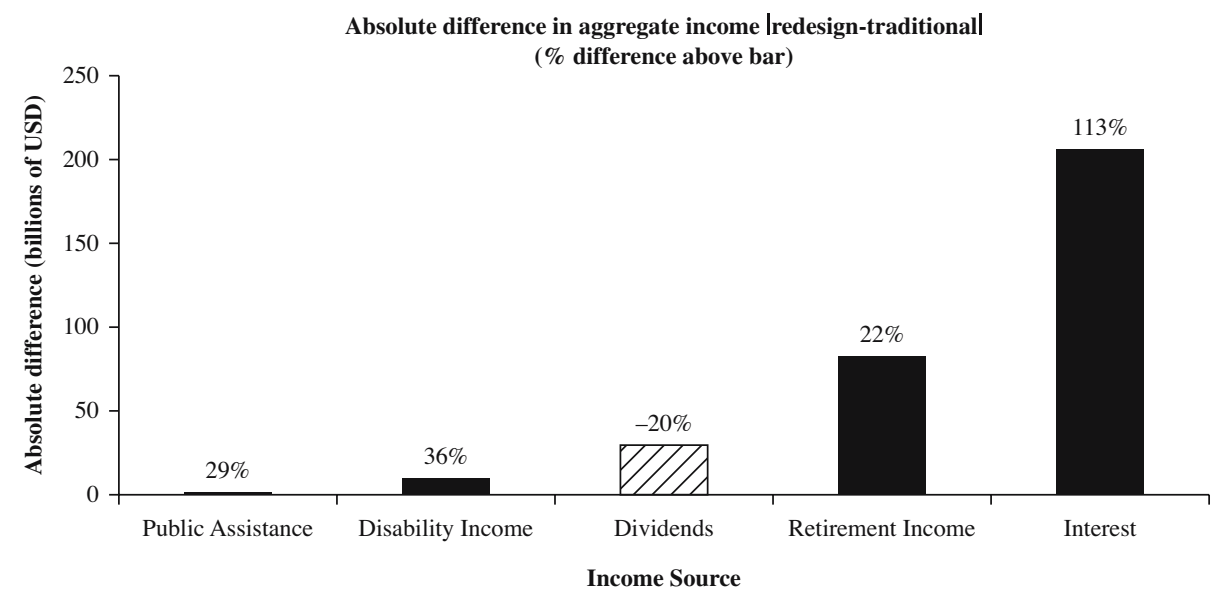

Fig. 1. Aggregate income differences between the traditional and redesign samples. Source: U.S. Census Bureau, Current Population Survey, 2014 Annual Social and Economic Supplement.

2) interest, and 3) dividends. These three sources had the largest difference in estimated aggregate income of the types affected by the redesign. Fig. 1 shows changes in aggregate income for all income sources with a statistically significant difference in aggregate income between the traditional and redesign samples. For interest income, the number of recipients increased by 37.6 million and aggregate income increased by USD 206.3 billion. For retirement income, the number of recipients increased by 1.8 million and aggregate income increased by USD 82.7 billion. For dividend income, the number of recipients decreased by 1.4 million and aggregate income decreased by USD 29.6 billion.

\section{Imputation Methodology}

\subsection{Hot Deck Imputation}

As a part of the standard processing of the CPS ASEC, when an individual does not respond to a particular question, missing values are imputed using a hot deck procedure. In the hot deck, individuals are divided into cells based on the characteristics specified in the hot deck model. Within each cell, individuals without missing information (donors) are randomly selected and their income is assigned to the individuals with missing information (recipients). Donors and recipients in each cell must match on every variable in the hot deck model. If there are no donors in a given recipient's cell, the hot deck model is amended to reduce the number of categories for some variables (for example from nine age groupings to six) and to reduce the number of variables in the model.

The different hot deck models used in the CPS ASEC are called match levels. The first match level includes the largest number of variables and categories within each variable. If no matches are found at the first level, an attempt to match recipients and donors is made using the model at the second match level. This continues until a match level is reached for a given recipient in which at least one donor is present in the same cell. For missing earnings in the longest job, at the first match level there are 16 variables in the model and 621 billion possible cells; at the second match level there are 14 variables and 17 billion 
possible cells; at the third match level there are eleven variables and 3.8 million possible cells, and by the sixth match level there are four variables and 96 possible cells. In the traditional sample for those observations missing earnings from the longest job only, $4.4 \%$ matched at the first level, $13.0 \%$ matched at the second level, 51.5\% matched at the third level, and $6.4 \%$ matched at the sixth level. The variables and number of categories at each match level are available in Supplemental data online (URL: http://dx.doi.org/10.1515/ JOS-2017-0010), Table 1.

As these numbers make clear, the number of variables that can be included in a hot deck model is limited by the size of the sample. While this is clearly a constraint even in the full CPS ASEC sample of about 200,000 individuals, the constraint is even more binding when imputing income from the redesign sample of about 60,000 individuals. If retirement, interest, and dividend income in the traditional sample were imputed using the hot deck model, it would not be possible to incorporate many variables in the model that are potentially correlated with each income type. This would limit the ability of the imputation to accurately match similar individuals as donors and recipients and reduce the quality of the matches.

\subsection{Model-Based Matching Imputation}

Instead, a more flexible technique is implemented to impute the missing responses to the redesigned questions in the traditional sample for the research file. The approach, developed by Bondarenko and Raghunathan (2007), hereafter BR, matches donors and recipients using summaries of covariates estimated by logistic and ordinary least squares regression modelling.

The primary reason the BR approach was chosen in this research is its similarity to the hot deck model. As in the hot deck model, individuals are matched based on similarities in observable characteristics. In the hot deck model, matching is directly based on the characteristics. In the BR approach, the matching is based on the predicted probability of recipiency and expected income conditional on recipiency, both of which can be estimated from observable characteristics. This is advantageous, as the imputed data must be comparable to data from subsequent years where all missing data are imputed using the hot deck model. However, by efficiently summarizing the model covariates in two statistics, recipiency and expected income, the BR approach allows for the inclusion of many more variables in the imputation model.

Next, the BR method is described, with slight modification for this application. Suppose that the dataset has $P$ variables of observable characteristics, $X_{p}, p=1,2, \ldots, P$ and $X=\left(X_{1}, \ldots, X_{P}\right)$ and $Q$ income types where $Y_{q}, q=1,2, \ldots, Q$, represents the income value and $R_{q}$ represents recipiency status $\left(R_{q} \in\{0,1\}\right)$. There are two groups in the sample, one for which the income types $q$ are observed (group $O$ ) and one for which income types $q$ are unobserved (group $M$ ) so that each vector can be partitioned among $O$ and $M$ as $X_{p}=\left(X_{p}^{O}, X_{p}^{M}\right), Y_{q}=\left(Y_{q}^{O}, Y_{q}^{M}\right)$, and $R_{q}=\left(R_{q}^{O}, R_{q}^{M}\right)$. Because missingness is complete for all $Y_{q}^{M}$, income can be imputed sequentially without iteration. Therefore, $<q$ is defined as the set of incomes with indices less than $q$ so that $Y_{<q}=\left(Y_{1}, \ldots, Y_{q-1}\right)$ and $R_{<q}=\left(R_{1}, \ldots, R_{q-1}\right)$ and $Y_{<1}$ and $R_{<1}$ are empty sets. Two efficient summaries are constructed of the income variables through two regression predictions: 
1. Probability of recipiency: $\hat{R}_{q}=\operatorname{Pr}\left(R_{q}=1 \mid Y_{<q}, R_{<q}, X\right)$ estimated using a logistic regression model. This is an efficient summary of $R_{q}$ that can be used to balance income recipients and nonrecipients.

2. $\hat{R}_{q}$ is stratified into $K$ equal size strata, where $k=1, \ldots, K$.

3. Predicted value of income conditional on recipiency within each stratum $k: \hat{Y}_{q}=$ $E\left(Y_{q} \mid R_{q}=1, Y_{<q}, R_{<q}, X\right)$ is estimated using an OLS regression model on all individuals in stratum $k$. Then, individuals are subdivided in stratum $k$ into $J$ equal sized substrata, where $j=1, \ldots, J$. This creates $K \times J$ equal size strata.

Within each stratum $k, j$ there are $n$ individuals with observed income and recipiency, and $m$ individuals with missing income and recipiency for income type $q$. A sample size $m$ is drawn from the observed set of $n$ individuals as the imputed values by Approximate Bayesian Bootstrap (ABB). This step is repeated for each stratum $k, j$ and income type $q$ and then sequentially for all $q=1, \ldots, Q$. This entire process is repeated independently to obtain multiple imputations.

This approach relies on the same assumption that underlies matching models (see, for example, Rosenbaum and Rubin 1983). The traditional sample is $M$ in this exercise, as the responses to the redesigned questions are missing for all individuals in the traditional sample. The redesign sample is $O$ as the responses are observed. For this approach to be valid, it must be assumed that inclusion in the traditional sample can be controlled for by the variables in the imputation model (unconfoundedness). Specifically, given the probability of missingness $P(M)$, it is assumed that $P\left(M \mid X, Y_{q}^{M}, Y_{q}^{O}\right)=P(M \mid X)$ where $X$ can be summarized by $\hat{R}_{q}$ and $\hat{Y}_{q}$. Although the random selection into the redesign sample implies missingness should be completely at random (MCAR), Mitchell and Renwick (2015) suggest that sample differences do exist on observable characteristics. Therefore, it is conservatively only assumed that the responses are missing at random (MAR).

There are a number of challenges to implementing BR method in the CPS ASEC. First, many income types do not follow a normal distribution or any simple transformation of a normal distribution. Because the missing income sources are modeled with continuous covariates, some distributional assumptions must be made about the relationships between them. Second, predictors $(X)$ must be selected for the modelling of each income variable from a very large set of possible covariates $(>1,200)$ in the CPS ASEC.

As shown in Hokayem et al. (2015), the distribution of income is rarely normally distributed. Simple transformation (such as log) and more flexible ones such as Tukey's gh distribution (He and Raghunathan 2006) also can fail to convert the distribution to normal. Therefore, an empirical normal transformation proposed by Woodcock and Benedetto (2009) is used to convert all income values to normal distributions (this includes income and other continuous variables in $X$ as well) prior to imputation.

The most significant challenge to applying the BR method to the CPS ASEC was to select the models for each imputed variable. In order to avoid omitted variable bias in the imputation model, as many potential predictors as possible should be included. However, if too many variables are included, overfitting the model is a risk. The list of potential predictors used includes all unchanged income information (imputation flag, recipiency, value), spouse/partner earnings, race (separate dummy for each), gender, age (including dummies for each age between 62 and 70), weeks worked last year, hours worked per 
week, as well as the hot deck categories for relationship to householder, education level, marital status, presence of children, occupation (22 categories), type of residence, Census region, recipiency of means-tested government transfers. A large set of interaction terms are included in the list of predictors, including for major income types (earnings, spouse earnings, etc.), education, weeks and hours worked, race and age, and means-tested transfers. In all, over 1,200 potential predictors and interaction terms can be included in the BR models. A list of the modelling variables is available in Supplemental data, Table 2 (URL: http://dx.doi.org/10.1515/JOS-2017-0010).

The parameters of two models are estimated: (1) $R_{q}=F\left(X_{q} \beta_{R}+v_{q}\right)$ using logistic regression and (2) $Y_{q}=X_{q} \beta_{Y}+e_{q}$ by OLS. However, with more than 1,000 possible covariates, all possible covariates cannot be included in $X$ and some values in $\beta$ must be set to 0 in each regression.

Stepwise model selection is used to determine which values in $\beta$ in each regression to set to 0 . It was chosen as a pragmatic tool to efficiently capture the correlations between covariates $X_{q}$ and dependent variables $R_{q}$ and $Y_{q}$. However, there is uncertainty about which are the correct items in each $\beta$ that should be set to zero which must be accounted for in order for the imputation to be proper. If the model variables were known with certainty (known nonzero items in $\beta$ ), after regressing $Y$ on $X \beta$ parameter uncertainty could be accounted for using the variance-covariance matrix of $\beta$. However, in this case, both parameter and model uncertainty are present. In order to approximate both sources of uncertainty and have proper imputation variance estimates, for each income type, all regressions for each income type $q$ are run on an approximate Bayes Bootstrap (ABB) sample.

In summary, the imputation steps to create the Income-Consistent file are:

1. Normal transformation - transform all income value variables to normal distribution with empirical normal transformation.

2. BR Imputation - sequentially impute interest, dividends, and retirement income from the redesign (donors/observed) to the traditional sample (recipients/missing). For each income type:

a. Select a random sample by $\mathrm{ABB}$.

b. Predict probability of income recipiency using logistic regression on the redesign ABB sample with stepwise model selection to choose list of predictors. Only those individuals with non-imputed values of recipiency are included in the regression.

c. Stratify the sample into $K$ equal-sized groups based on probability of income recipiency in the original sample.

d. Within each stratum $k$, predict expected income conditional on recipiency using OLS regression on the redesign ABB sample that is within the probability of recipiency bounds of that stratum.

e. Stratify subsample $k$ into $J$ equal sized substrata based on the expected income of the original sample.

f. Within each substratum $j$, select a random sample of $m$ donors from the redesign sample (where $m$ is the number of recipients with missing responses in stratum $k, j$ ) using $\mathrm{ABB}$. Each donor receives all income, source, and value variables from the recipient. By donating source information (i.e., whether the retirement income is 
from a 401k, IRA, or others), this implies the additional assumption that for each income type $q$ and source $S_{q}, P\left(M \mid X, Y_{q}^{M}, Y_{q}^{O}, S_{q}^{M}, S_{q}^{O}\right)=P(M \mid X)$, where $X$ can be summarized by $\hat{R}_{q}$ and $\hat{Y}_{q}$.

g. Repeat for each stratum $k, j$ until all missing observations for income type $q$ have been imputed.

3. Transform to original scale - return all variables to their original scales.

4. Repeat the entire process to create ten implicates.

These steps are done after processing and allocation of the survey data. This means that hot deck imputed values in the redesign file can be used as part of the imputation process. However, all modelling and prediction is done only on actual responses with allocated values excluded from the modelling step.

Since all of the interest, dividends, and retirement income are missing for all observations in the traditional sample, the order of imputation should not matter. Consider, for example, the case where interest is imputed first and dividends second. In that case, the imputation for interest should capture the relationship between interest and all other variables in $X_{<q}$. In the imputation for dividends, information on interest is included in $X_{<q}$, which should capture the relationship between dividends and interest as well as dividends and all other variables in $X$. For both missing income types, the imputation captures the conditional relationship between the other type and the variables in $X$. The same is true if dividends are imputed first and interest second. As a result, the variables are imputed by frequency of recipiency, from most common to least common: 1) interest, 2) dividends, and 3) retirement income. Note that this invariance to imputation order is only true if missingness for each imputed variable implies missingness for all others.

\section{Diagnostic Results}

One way of evaluating the imputation model is to construct an $R^{2}$ from the set of regressions on the ABB sample. For the logistic regressions, the Tjur- $R^{2}$ (Tjur 2009) is used, which is calculated by comparing the average predicted probability of recipiency for those who did and did not receive income of that type, or

$$
R_{\mathrm{Tjur}}^{2}=E\left(\hat{R}_{q} \mid R=1, Y_{<q}, R_{<q}, X\right)-E\left(\hat{R}_{q} \mid R=0, Y_{<q}, R_{<q}, X\right) .
$$

The Tjur- $R^{2}$ is bounded between 0 and 1 .

For the OLS regressions, the $R^{2}$ used is the squared correlation between the transformed income and the predicted income from the strata regressions, shown in Table 3 . The average Tjur- $R^{2}$ for interest, dividends, and retirement are $0.35,0.30$, and 0.39 respectively. The OLS $R^{2}$ values for interest, dividends, and retirement income are 0.12 , 0.10 , and 0.15 respectively.

The relatively low $R^{2}$ are in part due to the fact that predictions are made on $\mathrm{ABB}$ samples, not the original one. The regression $R^{2}$ are much higher, but they reflect the match between the predictions and the bootstrapped sample, which will by definition be higher than for the original sample, which was not used for the prediction.

After imputing interest, dividend, and retirement income responses for the traditional sample, the two samples are combined to create the Income-Consistent file, as all responses 
Table 3. Model diagnostics - effective $R^{2}$ of recipiency and value regressions.

\begin{tabular}{|c|c|c|c|c|c|c|}
\hline \multirow[b]{2}{*}{ Variable } & \multicolumn{3}{|c|}{ Recipiency } & \multicolumn{3}{|c|}{ Value } \\
\hline & Average & Min & Max & Average & Min & Max \\
\hline Interest & $\begin{array}{c}0.35 \\
(0.01)\end{array}$ & 0.33 & 0.36 & $\begin{array}{c}0.12 \\
(0.03)\end{array}$ & 0.05 & 0.15 \\
\hline Dividends & $\begin{array}{c}0.30 \\
(0.01)\end{array}$ & 0.28 & 0.32 & $\begin{array}{c}0.10 \\
(0.03)\end{array}$ & 0.03 & 0.13 \\
\hline Retirement & $\begin{array}{c}0.39 \\
(0.02)\end{array}$ & 0.36 & 0.43 & $\begin{array}{c}0.15 \\
(0.05)\end{array}$ & 0.03 & 0.19 \\
\hline
\end{tabular}

The $R^{2}$ are calculated by taking the predicted recipiency and values conditional on recipiency from the prediction models used to define the donor/recipient cells and calculating the Tjur $R^{2}$ for recipiency and squared correlation for the value. The average, minimum, and maximum effective $R^{2}$ across the 10 implicates are reported with standard deviations in parentheses.

are now consistent with the redesigned income questionnaire. Estimates are calculated for the number of recipients and mean income in the traditional, redesign, each of the IncomeConsistent implicates as well as the multiple imputation estimates, shown in Table 4. Standard errors in each file or implicate are calculated using replicate weights. Throughout the article, multiple imputation standard errors for the Income-Consistent file are calculated using the multiple imputation variance formula in Rubin and Schenker (1986). There are no statistically significant differences when comparing recipiency or mean income between the redesign and Income-Consistent files for any of the three income sources.

Another statistic that can be used to evaluate the value of applying the imputation to create the Income-Consistent file is the estimated rate of missing information, denoted by $\gamma$ (Rubin 1987). Very high values of $\gamma$ (for example, 0.7) would imply that there is little additional benefit to using the traditional sample with imputed interest, dividend, and retirement income. As the relevance of the missing interest, dividend, and retirement income may differ for different statistics, for each parameter of interest, a separate $\gamma$ can be computed.

I estimated $\gamma$ for the recipiency and mean income statistics in Table 4. Recall that approximately $30 \%$ of the Income-Consistent sample comes from the redesign sample and is the same across all ten implicates. The rate of missing information varies across the income types from 0.09 (interest recipiency) to 0.53 (mean retirement income).

I also calculated $\gamma$ for household median income and poverty of 0.15 and 0.08 respectively. Both of these are low values, which indicates that a considerable amount of information in estimating median income and poverty is contributed by the other variables in the traditional sample that were not imputed, as they were not affected by the redesign. For family and household income statistics, these low $\gamma$ values also validate the general approach of combining the samples to take full advantage of the information available in the questions unaffected by the redesign.

\section{Income and Poverty Statistics}

To further assess the Income-Consistent file, median income and poverty statistics are calculated. These statistics are in the annual Income and Poverty reports published by the 
Table 4. Recipiency and mean Income in traditional, redesign, and income-consistent files.

\begin{tabular}{|c|c|c|c|c|c|c|}
\hline & \multicolumn{2}{|c|}{ Retirement } & \multicolumn{2}{|c|}{ Interest } & \multicolumn{2}{|c|}{ Dividends } \\
\hline & $\begin{array}{l}\text { Recipiency } \\
\text { (Thousands) }\end{array}$ & $\begin{array}{l}\text { Mean } \\
\text { (USD) }\end{array}$ & $\begin{array}{l}\text { Recipiency } \\
\text { (Thousands) }\end{array}$ & $\begin{array}{l}\text { Mean } \\
\text { (USD) }\end{array}$ & $\begin{array}{l}\text { Recipiency } \\
\text { (Thousands) }\end{array}$ & $\begin{array}{l}\text { Mean } \\
\text { (USD) }\end{array}$ \\
\hline Traditional & $\begin{array}{l}18,871 \\
(251)\end{array}$ & $\begin{array}{c}20,034 \\
(307)\end{array}$ & $\begin{array}{c}86,142 \\
(588)\end{array}$ & $\begin{array}{c}2,120 \\
(68)\end{array}$ & $\begin{array}{c}33,243 \\
(432)\end{array}$ & $\begin{array}{l}4,424 \\
(170)\end{array}$ \\
\hline Redesign & $\begin{array}{c}20,698 \\
(372)\end{array}$ & $\begin{array}{c}22,262 \\
(449)\end{array}$ & $\begin{array}{l}1,23,772 \\
(887)\end{array}$ & $\begin{array}{l}3,142 \\
(107)\end{array}$ & $\begin{array}{c}31,804 \\
(568)\end{array}$ & $\begin{array}{l}3,693 \\
(211)\end{array}$ \\
\hline \multicolumn{7}{|l|}{$\begin{array}{l}\text { Income-Consistent } \\
\text { Implicate \# }\end{array}$} \\
\hline 1 & $\begin{array}{c}20,709 \\
(265)\end{array}$ & $\begin{array}{c}22,406 \\
(271)\end{array}$ & $\begin{array}{c}1,25,594 \\
(1,866)\end{array}$ & $\begin{array}{c}3,033 \\
(75)\end{array}$ & $\begin{array}{c}32,095 \\
(587)\end{array}$ & $\begin{array}{l}3,584 \\
(172)\end{array}$ \\
\hline 2 & $\begin{array}{c}20,777 \\
(292)\end{array}$ & $\begin{array}{c}22,195 \\
(377)\end{array}$ & $\begin{array}{c}1,24,925 \\
(1,404)\end{array}$ & $\begin{array}{c}3,160 \\
(75)\end{array}$ & $\begin{array}{c}32,045 \\
(411)\end{array}$ & $\begin{array}{l}3,669 \\
(141)\end{array}$ \\
\hline 3 & $\begin{array}{c}20,511 \\
(241)\end{array}$ & $\begin{array}{c}22,054 \\
(251)\end{array}$ & $\begin{array}{c}1,25,339 \\
(1,834)\end{array}$ & $\begin{array}{c}3,168 \\
(87)\end{array}$ & $\begin{array}{c}31,236 \\
(386)\end{array}$ & $\begin{array}{l}3,706 \\
(109)\end{array}$ \\
\hline 4 & $\begin{array}{c}20,395 \\
(225)\end{array}$ & $\begin{array}{c}22,383 \\
(257)\end{array}$ & $\begin{array}{c}1,25,813 \\
(2,152)\end{array}$ & $\begin{array}{c}3,083 \\
(54)\end{array}$ & $\begin{array}{c}31,657 \\
(368)\end{array}$ & $\begin{array}{c}3,734 \\
(96)\end{array}$ \\
\hline 5 & $\begin{array}{c}20,826 \\
(455)\end{array}$ & $\begin{array}{c}22,667 \\
(291)\end{array}$ & $\begin{array}{c}1,24,748 \\
(1,228)\end{array}$ & $\begin{array}{c}3,115 \\
(55)\end{array}$ & $\begin{array}{c}32,167 \\
(616)\end{array}$ & $\begin{array}{l}3,633 \\
(122)\end{array}$ \\
\hline 6 & $\begin{array}{c}20,945 \\
(428)\end{array}$ & $\begin{array}{c}22,371 \\
(287)\end{array}$ & $\begin{array}{c}1,24,858 \\
(1,282)\end{array}$ & $\begin{array}{c}3,087 \\
(49)\end{array}$ & $\begin{array}{c}31,357 \\
(366)\end{array}$ & $\begin{array}{l}3,923 \\
(133)\end{array}$ \\
\hline 7 & $\begin{array}{c}20,891 \\
(520)\end{array}$ & $\begin{array}{c}22,826 \\
(377)\end{array}$ & $\begin{array}{c}1,24,804 \\
(1,191)\end{array}$ & $\begin{array}{c}3,082 \\
(51)\end{array}$ & $\begin{array}{c}31,660 \\
(295)\end{array}$ & $\begin{array}{l}3,706 \\
(135)\end{array}$ \\
\hline 8 & $\begin{array}{c}20,659 \\
(248)\end{array}$ & $\begin{array}{c}22,252 \\
(267)\end{array}$ & $\begin{array}{c}1,25,513 \\
(2,129)\end{array}$ & $\begin{array}{c}3,195 \\
(75)\end{array}$ & $\begin{array}{c}31,827 \\
(404)\end{array}$ & $\begin{array}{l}3,629 \\
(129)\end{array}$ \\
\hline 9 & $\begin{array}{c}20,788 \\
(327)\end{array}$ & $\begin{array}{c}22,019 \\
(353)\end{array}$ & $\begin{array}{c}1,25,805 \\
(2,026)\end{array}$ & $\begin{array}{c}3,037 \\
(74)\end{array}$ & $\begin{array}{c}31,741 \\
(302)\end{array}$ & $\begin{array}{l}3,597 \\
(165)\end{array}$ \\
\hline 10 & $\begin{array}{c}20,793 \\
(418)\end{array}$ & $\begin{array}{c}21,867 \\
(393)\end{array}$ & $\begin{array}{c}1,25,996 \\
(2,189)\end{array}$ & $\begin{array}{c}3,134 \\
(58)\end{array}$ & $\begin{array}{c}31,733 \\
(312)\end{array}$ & $\begin{array}{l}3,711 \\
(116)\end{array}$ \\
\hline $\begin{array}{l}\text { Income-Consistent } \\
\text { Multiple Imputation }\end{array}$ & $\begin{array}{c}20,729 \\
(398)\end{array}$ & $\begin{array}{c}22,304 \\
(442)\end{array}$ & $\begin{array}{c}1,25,340 \\
(1,841)\end{array}$ & $\begin{array}{c}3,109 \\
(88)\end{array}$ & $\begin{array}{c}31,752 \\
(525)\end{array}$ & $\begin{array}{l}3,689 \\
(168)\end{array}$ \\
\hline $\begin{array}{l}\text { Rate of Missing } \\
\text { Information }(\gamma)\end{array}$ & 0.23 & 0.53 & 0.09 & 0.47 & 0.41 & 0.41 \\
\hline
\end{tabular}

Source: U.S. Census Bureau, Current Population Survey, 2014 Annual Social and Economic Supplement. Standard errors (in parenthesis) are calculated using replicate weights. For more information, see "Standard Errors and Their Use" at <www.census.gov/hhes/www/p60_245sa.pdf $>$. Standard errors for the IncomeConsistent file are calculated using the multiple imputation formula in Rubin and Schenker (1986).

Census Bureau from the CPS ASEC (available at http://www.census.gov/topics/ income-poverty/income.html). Table 5 shows the median income statistics (Table 1 from the annual report) comparison between the Income-Consistent full sample and the traditional and redesign sample. Compared with the redesign sample, the only statistically significant differences are for median income of nonfamily households with a female householder (3.6\% greater) and households headed by individuals without a disability ( $2.3 \%$ greater). At the $90 \%$ confidence interval, fewer than ten percent of the tested statistics are significantly different. For the comparison with the traditional sample, nearly all of the median income comparisons are statistically significant.

Table 6 compares poverty estimates in each of the traditional and redesign sample to the Income-Consistent file. The headline poverty number for all individuals is not statistically significantly different between the Income-Consistent file and either sample. However, for the traditional sample, poverty is lower in the Income-Consistent file for blacks $(1.0 \%)$, 


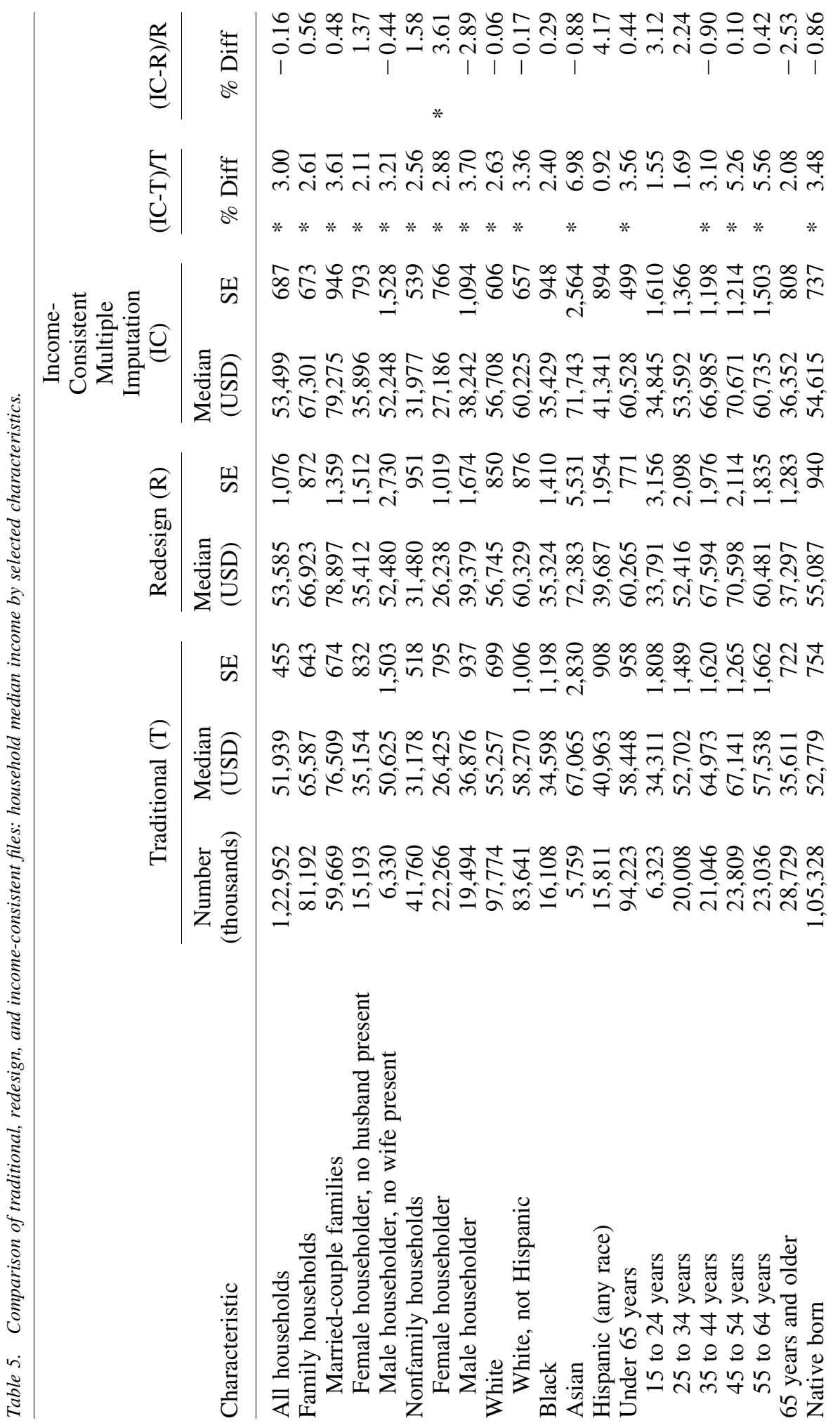




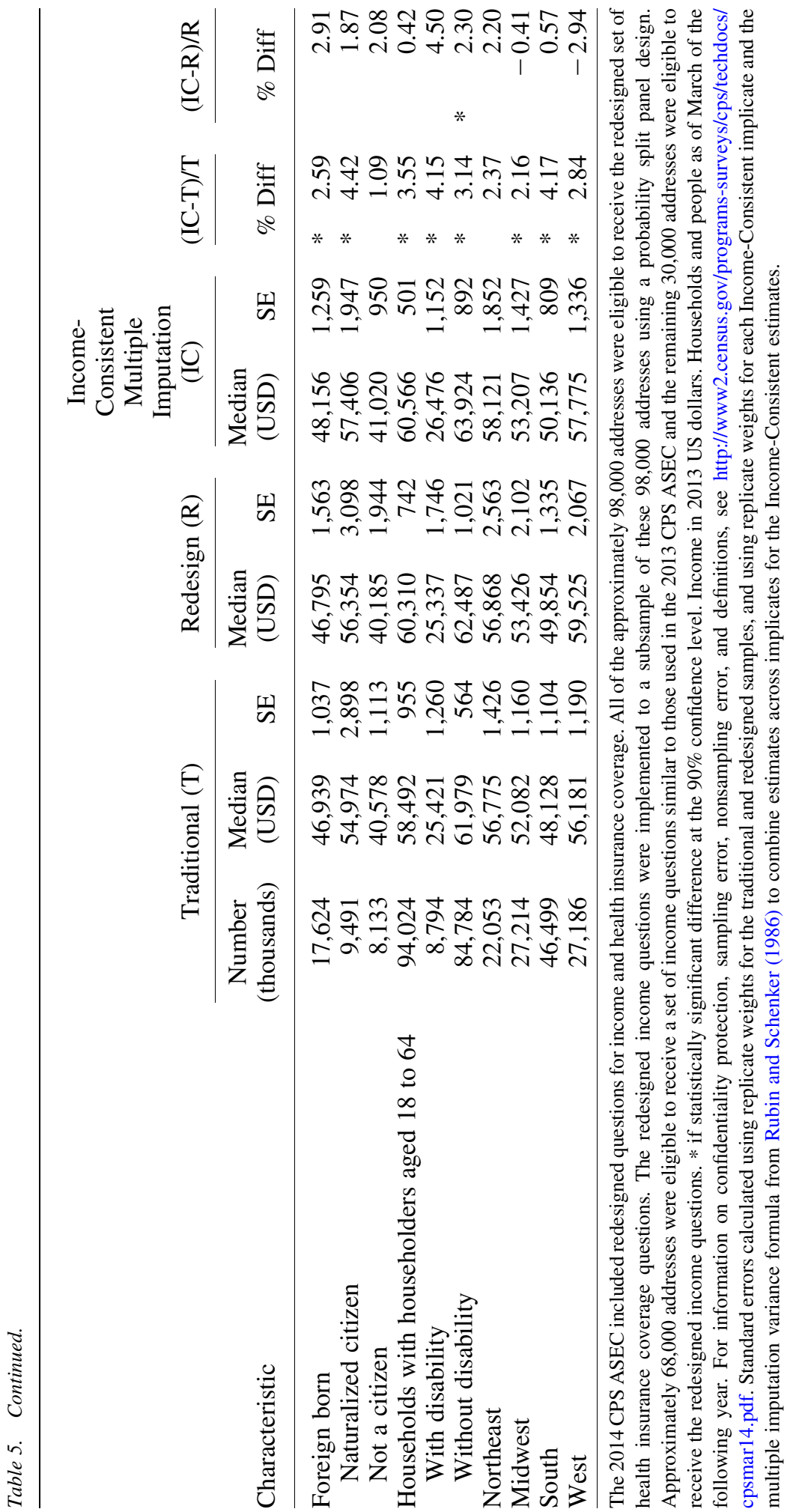




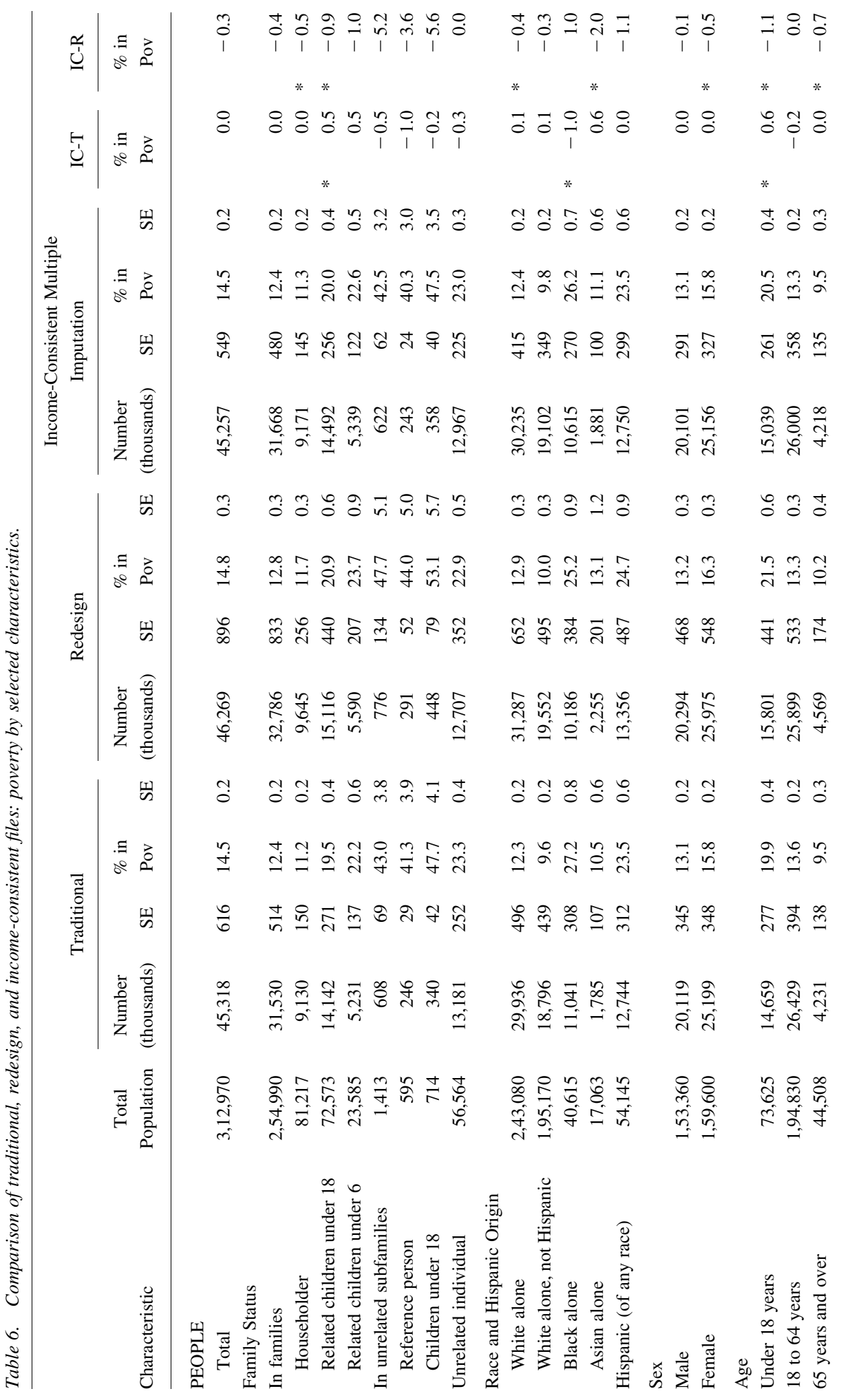




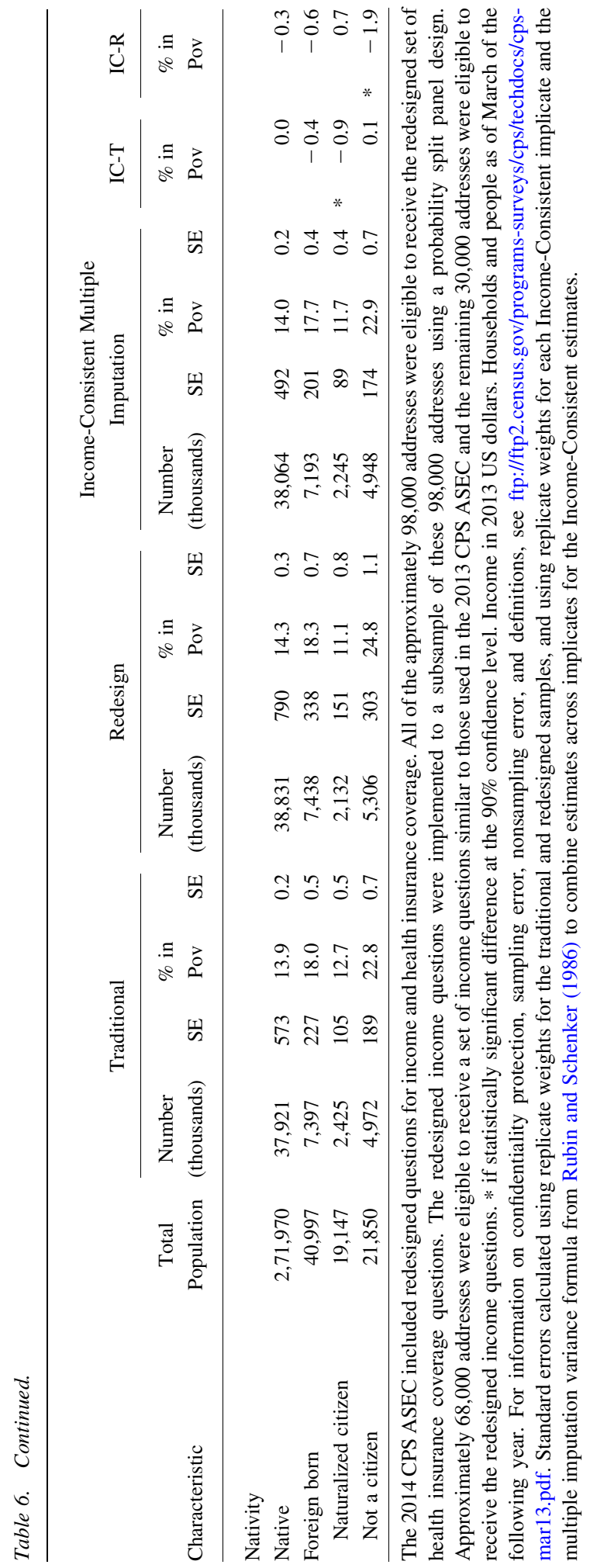


naturalized citizens $(-0.9 \%)$, residents of principal cities $(0.5 \%)$, and workers $(0.2 \%)$, and is higher for children $(0.6 \%)$. For the redesign sample, unlike median income, there are significant differences: lower in poverty in the Income-Consistent file for children $(1.1 \%)$ and those aged 65 and older $(0.7 \%)$.

To summarize the results, the Income-Consistent file household median income estimates are more like the redesign file, but the poverty estimates lie between the two files. While the point estimate for poverty of $14.5 \%$ is not statistically significantly different from the point estimate for either file, it is much closer to the $14.5 \%$ estimate from the traditional file than the $14.8 \%$ estimate of the redesign file.

\section{Conclusion}

In this article, multiple imputation is applied to the problem of a split sample receiving different survey instruments in a bridge year. One possible way to use data from all survey respondents is shown, even though distinct sets of respondents answered different questions. This idea has an important potential benefit - by making use of all of the data during a bridge year, it potentially lowers the cost in terms of decreased statistical power of survey redesigns and bridges.

To address this problem of missing information during a survey bridge year, a semiparametric multiple imputation technique proposed by Bondarenko and Raghunathan is applied to the CPS ASEC 2014 redesign. The technique performs reasonably well and analysis of basic summary statistics shows how this technique affects important economic statistics that are widely reported on from the CPS ASEC.

For the 2014 CPS ASEC, this technique increases the potential sample that can be used to make comparisons to data from subsequent years, which uses the redesigned questionnaire for the entire sample. The larger sample facilitates analyses on subgroups, such as by state, where the redesign sample may lack the statistical power needed for comparisons. By combining the two samples, this technique may also address concerns about differences in sample composition raised in previous research by Mitchell and Renwick (2015).

\section{References}

Bondarenko, I. and T.E. Raghunathan. 2007. "Multiple Imputations Using Sequential Semi and Nonparametric Regressions." In Proceedings Section on Survey Research Methods: American Statistical Association, July 29, 2007. 3293-3300. Salt Lake City, UT. Available at: http://ww2.amstat.org/sections/srms/Proceedings/y2007/Files/ JSM2007-000624.pdf (accessed November 2016).

Clogg, C.C., D.B. Rubin, N. Schenker, B. Schultz, and L. Weidman. 1991. "Multiple Imputation of Industry and Occupation Codes in Census Public-use Samples Using Bayesian Logistic Regression." Journal of the American Statistical Association 86: 68-78. Doi: http://dx.doi.org/10.1080/01621459.1991.10475005.

Czajka, J.L. and G. Denmead. 2008. "Income Data for Policy Analysis: A Comparative Assessment of Eight Surveys.” Mathematica Reference No.: 6302-601. Available at: 
https://www.mathematica-mpr.com/ /media/publications/PDFs/incomedata.pdf (accessed November 2016).

Hokayem, C., T.E. Raghunathan, and J. Rothbaum. 2015. "SRMI in the CPS ASEC." Unpublished Manuscript.

He, Y. and T.E. Raghunathan. 2006. “Tukey's gh Distribution for Multiple Imputation.”

The American Statistician 60: 251-256. Doi: http://dx.doi.org/10.1198/00031300 $6 \mathrm{X} 126819$.

Hicks, W. and J. Kerwin. 2011. "Cognitive Testing of Potential Changes to the Annual Social and Economic Supplement of the Current Population Survey." Unpublished Westat report to the U.S. Census Bureau. July 25, 2011.

Butrica, B.A., I. Howard, K.E. Smith, and E.J. Toder. 2009. "The Disappearing Defined Benefit Pensions and Its Potential Impact on the Retirement Income of Baby Boomers." Social Security Bulletin 69: 1-28.

Meyer, B.D., W.K.C. Mok, and J.X. Sullivan. 2009. "The Under-Reporting of Transfers in Household Surveys: its Nature and Consequences." National Bureau of Economic Research Working Paper \#15181.

Mitchell, J. and T. Renwick. 2015. "A Comparison of Official Poverty Estimates in the Redesigned Current Population Survey Annual Social and Economic Supplement.” U.S. Census Bureau SEHSD Working Paper \#2014-35.

Rosenbaum, P.R. and D.B. Rubin. 1983. "The Central Role of the Propensity Score in Observational Studies for Causal Effects.” Biometrika 70: 41-55. Doi: http://dx.doi. org/10.1093/biomet/70.1.41.

Rothbaum, J. 2015. "Comparing Income Aggregates: How Do the CPS and ACS Match the National Income and Product Accounts, 2007-2012." U.S. Census Bureau SEHSD Working Paper \#2015-01.

Rubin, D.B. 1987. Multiple Imputation for Nonresponse in Surveys. John Wiley and Sons. Doi: http://dx.doi.org/10.1002/9780470316696.

Rubin, D.B. and N. Schenker. 1986. "Multiple Imputation for Interval Estimation from Simple Random Samples with Ignorable Nonresponse." Journal of the American Statistical Association 81: 366-374. Doi: http://dx.doi.org/10.1080/01621459.1986. 10478280.

Schenker, N. and J.D. Parker. 2003. "From Single-Race Reporting to Multiple-Race Reporting: Using Imputation Methods to Bridge the Transition." Statistics in Medicine 22: 1571-1587. Doi: http://dx.doi.org/10.1002/sim.1512.

Semega, J. and E. Welniak Jr. 2013. "Evaluating the 2013 CPS ASEC Income Redesign Content Test." Presented at the proceeding of the 2013 FCSM Conference. U.S. Census Bureau Income Statistics Working Paper. Available at: http://census.gov/library/ working-papers/2013/demo/semega-01.html (accessed November 2016).

Semega, J. and E. Welniak Jr. 2015. "The Effects of the Changes to the Current Population Survey Annual Social and Economic Supplement on Estimates of Income.” Presented at the Proceedings of the 2015 Allied Social Science Association (ASSA) Research Conference. U.S. Census Bureau Income Statistics Working Paper. Available at: http://www.census.gov/library/working-papers/2015/demo/cpsasec-red-income. html (accessed November 2016). 
Tjur, T. 2009. "Coefficients of Determination in Logistic Regression Models-A New Proposal: The Coefficient of Discrimination." The American Statistician 63: 366-372. Doi: http://dx.doi.org/10.1198/tast.2009.08210.

Woodcock, S.D. and G. Benedetto. 2009. "Distribution-Preserving Statistical Disclosure Limitation.” Computational Statistics \& Data Analysis 53: 4228-4242. Doi: http://dx. doi.org/10.1016/j.csda.2009.05.020.

Received November 2015

Revised December 2016

Accepted December 2016 